\title{
The effect of the internal magnetism of ferromagnetic catalysts on their catalytic activity toward oxygen reduction reaction under an external magnetic field
}

\author{
Li Wang ${ }^{1}$ - Huijuan Yang ${ }^{2}$ - Juan Yang ${ }^{2}$ Yixin Yang ${ }^{2} \cdot$ Rongfang Wang ${ }^{2}$. \\ Shunxi $\mathrm{Li}^{2} \cdot$ Hui Wang ${ }^{2} \cdot$ Shan $\mathrm{Ji}^{3}$
}

Received: 14 April 2016/Revised: 15 May 2016/Accepted: 26 May 2016

(C) The Author(s) 2016. This article is published with open access at Springerlink.com

\begin{abstract}
In the oxygen reduction reaction (ORR), the oxygen transport rate plays an important role in the ORR on the cathode. An approach by applying magnetic fields on the cathode can effectively improve the oxygen transport. However, no work reports the effect of the magnetism of ferromagnetic catalysts on ORR under an external magnetic field. Herein, the catalytic performances of the ferromagnetic catalysts including $\mathrm{Fe}_{3} \mathrm{O}_{4}, \gamma-\mathrm{Fe}_{2} \mathrm{O}_{3}$, and $\mathrm{Fe}-\mathrm{N}-\mathrm{C}$ for ORR are studied under an external magnetic field. Linear sweep voltammetry (LSV) results indicate that the ORR current on the cathode increases with the strength of the external magnetic field due to the improved oxygen transfer. Meanwhile, the increase of the ORR current on Fe-N-C is larger than $\mathrm{Fe}_{3} \mathrm{O}_{4}$ and $\gamma-\mathrm{Fe}_{2} \mathrm{O}_{3}$ since some internal tiny magnetic fields generated by the $\mathrm{Fe}_{3} \mathrm{O}_{4}$ and $\gamma-\mathrm{Fe}_{2} \mathrm{O}_{3}$ catalysts are different from the magnetic direction of the external magnet. It is also found that the magnetic direction of the external magnet does not have any effect on the oxygen transfer.
\end{abstract}

Keywords Ferromagnetic catalysts · Magnetic field ·

Oxygen reduction reaction - Oxygen transfer .

Magnet direction

Shan Ji

jissshan@126.com

1 School of Chemistry \& Environmental Engineering, Pingdingshan University, Pingdingshan 467000, China

2 College of Chemistry and Chemical Engineering, Northwest Normal University, Lanzhou 730070, China

3 Department Chemical Engineering, University College London, London WC1E 7JE, UK

\section{Introduction}

The sluggish heterogeneous catalysis-oxygen reduction reaction is the main challenge for practical applications in fuel cells and metal-air batteries [1]. The efficiency of ORR depends on not only the catalytic activity of cathode catalysts but also the oxygen transport rate that is affected by the presence of water. Among various cathode catalysts, Pt-based materials are known as the most promising ORR electrocatalysts, but their large-scale application was constrained by their scarcity, prohibitive cost, and limited durability of noble metals [2, 3]. Therefore, a concerted effort has been devoted to develop low-cost ORR catalysts with competitive activity and durability, such as transition metal oxides, $\mathrm{Fe}_{3} \mathrm{O}_{4}$ [4], $\mathrm{MnO}_{2}$ [5], and metal-free carbon catalysts [6].

At the same time, some researchers paid attention to the approaches of improving the oxygen transfer rate on the cathode, such as the reactor design and operating conditions, and further enhance the performance of the cathode [7, 8]. Among these approaches, applying magnetic fields on the cathode was found to be an effective way to improve the oxygen transfer rate [9]. In 2001, Wakayama's group reported that the electrochemical flux was enhanced when a magnet field was applied to $\mathrm{Pt} / \mathrm{C}$ cathode by setting a permanent magnet behind it and oxygen gas was supplied toward a strong magnetic field, and the ORR current increased with the strength of the magnetic field $[10,11]$. Furthermore, Wakayama's group also reported that the main mechanism is that the Kelvin (magnetic) force promotes the transfer of paramagnetic oxygen molecular in the cathode of a fuel cell system [12-14]. As expected, an extended Pt electrode which has its own embedded permanent magnets exhibits good catalytic activity toward ORR. It was reported that the ORR current in an alkaline medium increased by a factor of three when the electrode was in a magnetized state [15]. 
In addition, the internal tiny magnetic fields of ferromagnetic catalysts can also be applied to fuel cells to affect the discharge performance on the cathode. Shi et al. reported that, at a low $\mathrm{Fe}_{3} \mathrm{O}_{4}$ /polyaniline load density on the cathode electrode in a zinc air fuel cell, the tiny magnetic field can promote oxygen transfer, increase the electric double-layer capacitance, lower the charge transfer resistance, and improve the discharge performance. But, when the load density is higher than $7.11 \mathrm{mg} \mathrm{cm}^{-2}$, the internal tiny magnetic fields inhibit oxygen transfer because of the interactions between the different magnetic poles [16]. Zeng et al. reported that the ferromagnetic $\mathrm{PtFe} / \mathrm{C}$ catalyst for ORR outperformed the paramagnetic $\mathrm{PtFe} / \mathrm{C}$ catalyst due to the magnetic force generated by catalyst particles [17]. However, under an external magnetic field, the effect of the strength of the internal tiny magnetic field of ferromagnetic catalysts on the catalytic activity toward ORR was not investigated in these above-mentioned reports. Herein, we aim to investigate the effect of the magnetism of ferromagnetic catalysts on its catalytic activity toward ORR under an external magnetic field. The effect of the direction of the external magnetic field was also studied.

\section{Experimental}

\section{Preparation of catalysts}

$\mathrm{Fe}_{3} \mathrm{O}_{4}$ and $\gamma-\mathrm{Fe}_{2} \mathrm{O}_{3}$ were purchased from Daoking Company, Beijing (AR.) and used as received from supplierswithout any further treatment. N, Fe-doped Vulcan carbon XC-72 catalyst (Fe-N-C) was prepared according to our previous work [18]. The detailed procedure was as follows: $100 \mathrm{mg}$ of peptone (CP. Fuchen Co., Tianjin, China) was ultrasonically dissolved in $5 \mathrm{~mL}$ of ultra-pure water in a $100-\mathrm{mL}$ flask, into which $10 \mathrm{mg}$ of $\mathrm{Fe}\left(\mathrm{NO}_{3}\right)_{3} \cdot 9 \mathrm{H}_{2} \mathrm{O}$ (AR. Kaixin Co., Tianjin, China) was added with stirring. One hundred milligrams of Vulcan XC-72 carbon black (AR. Carbot Corp.) was dispersed into the above solution with stirring, followed by drying at $70{ }^{\circ} \mathrm{C}$. The dried sample was heated under $\mathrm{N}_{2}$ flow at $800{ }^{\circ} \mathrm{C}$ for $2 \mathrm{~h}$ and then cooled down. The resulting powder was immersed in $\mathrm{HNO}_{3}$ solution $\left(2 \mathrm{~mol} \mathrm{~L}{ }^{-1}\right)$ for $24 \mathrm{~h}$ with stirring to remove unstable Fe species, then washed with deionized water until the $\mathrm{pH}$ of the filtrate was neutral and finally dried at $60{ }^{\circ} \mathrm{C}$ for $12 \mathrm{~h}$. The Fe-N-C was obtained.

\section{Physical characterization}

X-ray diffraction (XRD) patterns were obtained on a Shimadzu XD-3A (Japan), using filtered $\mathrm{Cu}-\mathrm{K}_{\alpha}$ radiation (40 kV, $30 \mathrm{~mA})$. Scanning electron microscopy (SEM) images were obtained on a Carl Zeiss Ultra Plus. Magnetization loops were measured using vibrating sample magnetometry (VSM), on a MicroSense EV9 measurement system. The $\mathrm{N}_{2}$ sorption isotherm was performed on a Quanta-chrome Autosorb-1 volumetric analyzer.

\section{Electrochemical characterization}

The electrochemical measurements were performed using an electrochemical workstation (CHI650). A common threeelectrode electrochemical cell was used for measurements. The counter and reference electrodes used were a platinum wire and an $\mathrm{Ag} / \mathrm{AgCl}$ (saturated $\mathrm{KCl}$ solution) electrode, respectively. The working electrode was a glassy carbon disk ( $5 \mathrm{~mm}$ in diameter). The thin-film electrode was prepared as follows: $2 \mathrm{mg}$ of catalyst and $1 \mathrm{mg}$ of XC-72 vulcan carbon (to improve the conductivity of the catalyst film) were dispersed ultrasonically in $0.4 \mathrm{~mL}$ Nafion/ethanol ( $0.25 \%$ Nafion) solution, and $8 \mu \mathrm{L}$ of the above solution was pipetted on the glassy carbon surface and dried at room temperature. Prior to the electrode activation, the electrolyte was degassed with nitrogen. Thereafter, the working electrode was activated by cycling in $0.1 \mathrm{~mol} \mathrm{~L}^{-1} \mathrm{KOH}$ electrolyte between 0 and $1 \mathrm{~V}$ at a scan rate of $50 \mathrm{mV} \mathrm{s}^{-1}$ until a reproducible voltammogram response was obtained. The electrolyte was then saturated with pure oxygen and oxygen flow was maintained during experiments of ORR testing. All currents were normalized by the geometric area of the electrode $\left(0.196 \mathrm{~cm}^{2}\right)$. All potentials initially measured versus the $\mathrm{Ag} / \mathrm{AgCl}$ electrode were converted to the reversible hydrogen electrode (RHE).

The prepared three-electrode system was settled in a magnetic field produced by a homemade direct-current solenoid (Fig. 1). The magnetic strength of $0.19,0.37$, or $0.56 \mathrm{~T}$ can be applied to the three-electrode system according to the following equation:

$B=\mu_{0} I(n / L)$

where $B$ is the magnetic strength, $\mu_{0}$ is the vacuum permeability, $I$ is the current intensity, and $n / L$ is the number of turns per length. The magnetic field is generated by a solenoid coil. In order to keep the temperature at $25^{\circ} \mathrm{C}$, the three-electrode cell

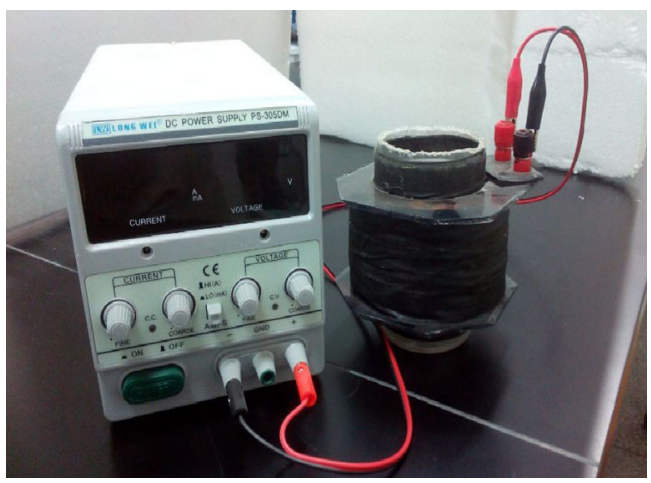

Fig. 1 Photograph of a homemade direct-current solenoid 

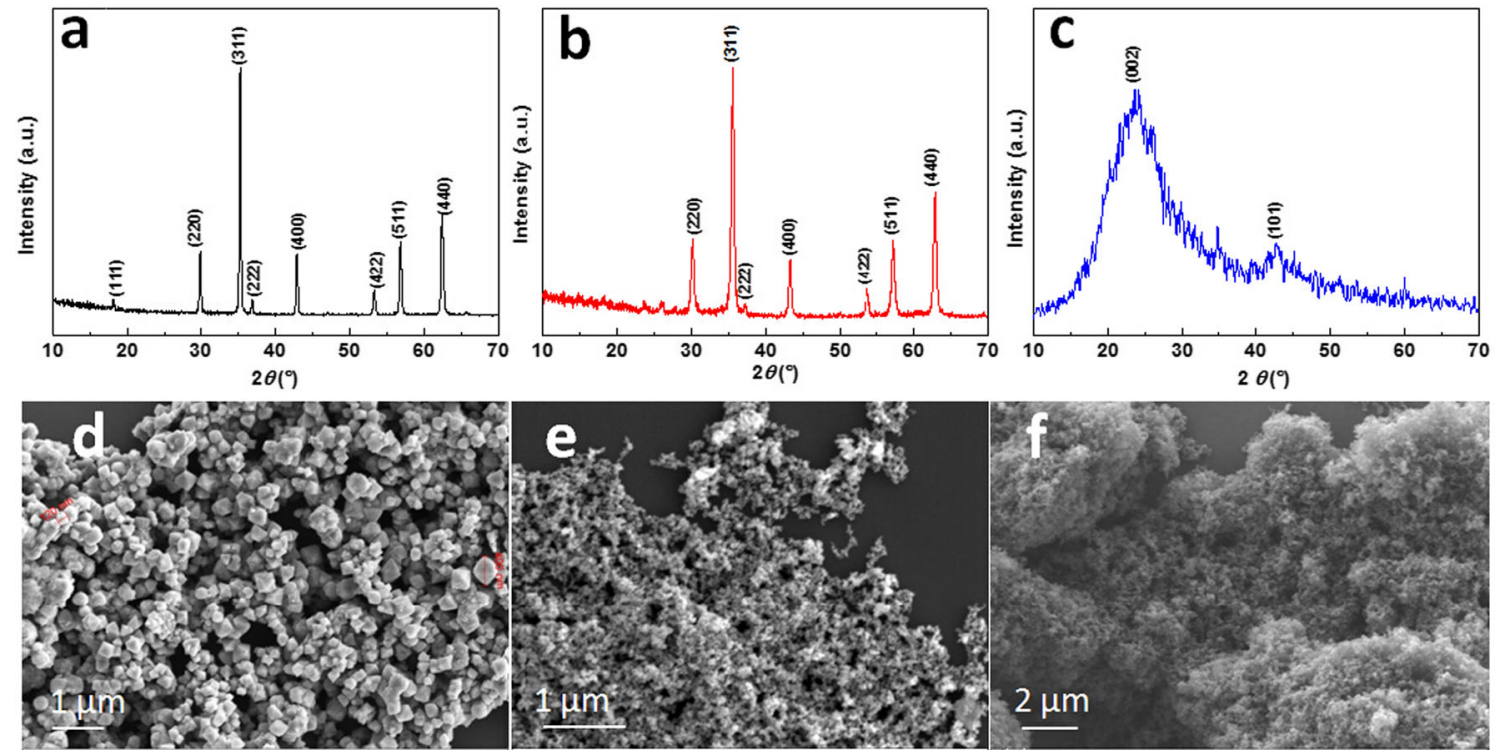

Fig. 2 XRD patterns of $\mathrm{Fe}_{3} \mathrm{O}_{4}(\mathbf{a}), \gamma-\mathrm{Fe}_{2} \mathrm{O}_{3}(\mathbf{b})$, and $\mathrm{Fe}-\mathrm{N}-\mathrm{C}(\mathbf{c})$; SEM images of $\mathrm{Fe}_{3} \mathrm{O}_{4}(\mathbf{d}), \gamma-\mathrm{Fe}_{2} \mathrm{O}_{3}(\mathbf{e})$, and $\mathrm{Fe}-\mathrm{N}-\mathrm{C}$ (f)

was wrapped by a water pipe, and water at a temperature of $25{ }^{\circ} \mathrm{C}$ flows through it during the experiment.

\section{Results and discussion}

The crystal structures of the purchased $\mathrm{Fe}_{3} \mathrm{O}_{4}, \gamma-\mathrm{Fe}_{2} \mathrm{O}_{3}$, and as-prepared Fe-N-C samples were characterized by XRD. As shown in Fig. 2a, the diffraction pattern of the planes (111), (220), (311), (222), (400), (422), (511), and (440) at $2 \theta$ values of $18.1^{\circ}, 29.9^{\circ}, 35.3^{\circ}, 37.0^{\circ}, 42.9^{\circ}, 53.3^{\circ}, 56.8^{\circ}$, and $62.4^{\circ}$, respectively, proves the presence of $\mathrm{Fe}_{3} \mathrm{O}_{4}$ [19]. Its average crystallite size calculated through the Scherrer formula [20] of the (311) plane is about $250 \mathrm{~nm}$. In the case of $\gamma-\mathrm{Fe}_{2} \mathrm{O}_{3}$ (Fig. 2b), the peaks at $18.1^{\circ}, 30.2^{\circ}, 35.6^{\circ}, 37.2^{\circ}, 43.2^{\circ}$, $53.6^{\circ}, 57.3^{\circ}$, and $62.9^{\circ}$ are the typical diffraction pattern of $\gamma-\mathrm{Fe}_{2} \mathrm{O}_{3}$ [21]. The estimated crystallite size of $\gamma-\mathrm{Fe}_{2} \mathrm{O}_{3}$ is $20 \mathrm{~nm}$. The Fe-N-C sample in Fig. 2c exhibits two peaks at about $24.4^{\circ}$ and $42.8^{\circ}$, which could be ascribed to the (002) and (101) plane of the graphitic structure [22].

SEM images of $\mathrm{Fe}_{3} \mathrm{O}_{4}, \gamma-\mathrm{Fe}_{2} \mathrm{O}_{3}$, and $\mathrm{Fe}-\mathrm{N}-\mathrm{C}$ are present in Fig. 2d-f. As seen in Fig. 2d, $\mathrm{Fe}_{3} \mathrm{O}_{4}$ mostly consists of octahedral particles, and there is also a small amount of irregular polyhedron particles in the SEM image. Its size ranges from 150 to $400 \mathrm{~nm}$. The SEM image in Fig. 2e reveals $\gamma-\mathrm{Fe}_{2} \mathrm{O}_{3}$ particles have a sphere-like morphology, and the size of the spheres is ca. $20 \mathrm{~nm}$. The Fe-N-C sample displays clusters of carbon spheres, which is similar to our previous report [18].

The porous structures of $\mathrm{Fe}_{3} \mathrm{O}_{4}, \gamma-\mathrm{Fe}_{2} \mathrm{O}_{3}, \mathrm{XC}-72$, and Fe$\mathrm{N}-\mathrm{C}$ were studied by nitrogen sorption isotherm and presented in Fig. 3. For $\mathrm{Fe}_{3} \mathrm{O}_{4}$, the adsorbed $\mathrm{N}_{2}$ volume is very little, implying there are very little pores that existed in the bulk $\mathrm{Fe}_{3} \mathrm{O}_{4}$. The curve of $\gamma-\mathrm{Fe}_{2} \mathrm{O}_{3}$ shows a loop at high relative pressure, suggesting mesopores existed in the $\gamma-\mathrm{Fe}_{2} \mathrm{O}_{3}$ structure [23]. Both XC-72 and Fe-N-C exhibit the representative type II nitrogen isotherm curve, which is related to the micropore structure [18]. The pore size distribution is shown in the inset of Fig. 3. Micro- and mesopores are found in the structure of $\gamma-\mathrm{Fe}_{2} \mathrm{O}_{3}, \mathrm{XC}-72$, and $\mathrm{Fe}-\mathrm{N}-\mathrm{C}$.

Magnetic hysteresis (M-H) loops of the three samples were measured at room temperature, and the data are presented in Fig. 4. As shown in Fig. 4, three samples have ferromagnetic property at room temperature. The value of saturation magnetization $\left(M_{\mathrm{s}}\right)$ is $86.3,68.5$, and $0.78 \mathrm{emu} \mathrm{g}^{-1}$ for $\mathrm{Fe}_{3} \mathrm{O}_{4}, \gamma$ $\mathrm{Fe}_{2} \mathrm{O}_{3}$, and $\mathrm{Fe}-\mathrm{N}-\mathrm{C}$, respectively.

Okada et al. found that a rotating working electrode eliminates the oxygen diffusion barrier in solution and thus enhances the effect of the magnetic field more than on a stationary electrode in an electrochemical cell [11]. Therefore, in this work, the catalysts loaded on the rotating

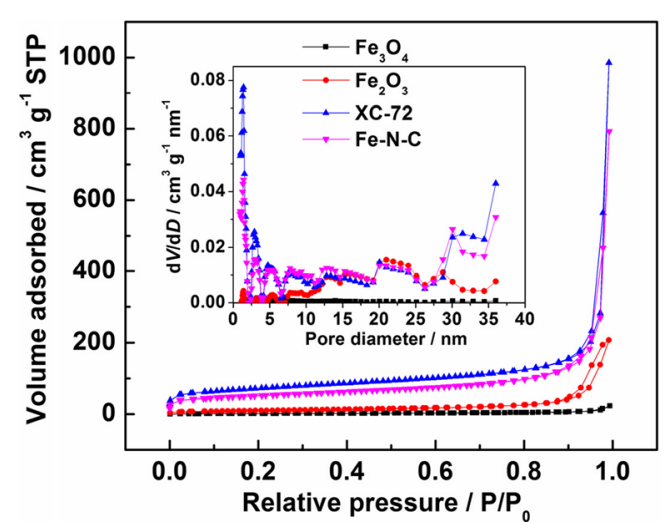

Fig. $3 \mathrm{~N}_{2}$ isotherms and the corresponding pore size distribution (inset) of $\mathrm{Fe}_{3} \mathrm{O}_{4}, \gamma-\mathrm{Fe}_{2} \mathrm{O}_{3}, \mathrm{XC}-72$, and $\mathrm{Fe}-\mathrm{N}-\mathrm{C}$ 
Fig. 4 Magnetic hysteresis loops of $\mathrm{Fe}_{3} \mathrm{O}_{4}(\mathbf{a}), \gamma-\mathrm{Fe}_{2} \mathrm{O}_{3}(\mathbf{b})$, and $\mathrm{Fe}-\mathrm{N}-\mathrm{C}(\mathbf{c})$. The corresponding inset shows a magnification of the hysteresis loop near zero fields
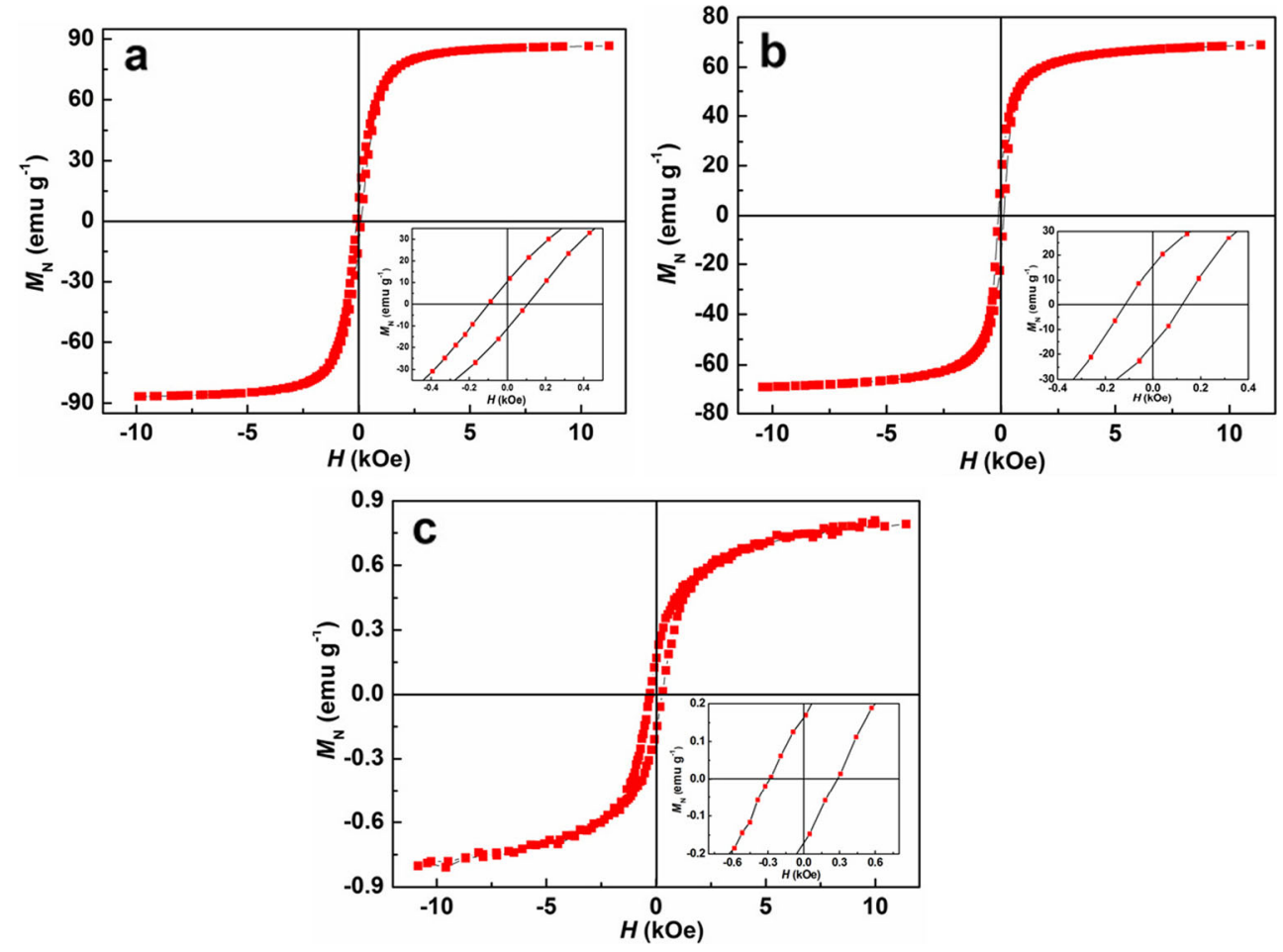

disk electrode were used as a working electrode. Figure 5 shows the cyclic voltammograms (CVs) of $\mathrm{Fe}_{3} \mathrm{O}_{4}$ (a), $\gamma$ $\mathrm{Fe}_{2} \mathrm{O}_{3}(\mathrm{~b})$, and $\mathrm{Fe}-\mathrm{N}-\mathrm{C}$ electrodes, which were measured in a $\mathrm{N}_{2}$ - or $\mathrm{O}_{2}$-saturated $0.1 \mathrm{~mol} \mathrm{~L}^{-1} \mathrm{KOH}$ solution at a scan

rate of $50 \mathrm{mV} \mathrm{s}^{-1}$ with and without the external magnetic field. For the all three catalysts, CVs in the potential range from -1.0 to $+0.2 \mathrm{~V}$ exhibited similar featureless curves. With the presence of $\mathrm{N}_{2}$ atmosphere, no obvious redox peaks
Fig. 5 Cyclic voltammograms of $\mathrm{Fe}_{3} \mathrm{O}_{4} / \mathrm{C}(\mathbf{a}), \gamma-\mathrm{Fe}_{2} \mathrm{O}_{3} / \mathrm{C}(\mathbf{b})$, and $\mathrm{Fe}-\mathrm{N}-\mathrm{C}(\mathbf{c})$ at a potential scan rate of $50 \mathrm{mV} \mathrm{s}^{-1}$; electrolyte:

$0.1 \mathrm{~mol} \mathrm{~L}^{-1} \mathrm{KOH}$; black solid lines the electrolyte saturated with $\mathrm{N}_{2}$ and without the presence of the external magnetic field; red dashed lines the electrolyte saturated with $\mathrm{O}_{2}$ and without the presence of the external magnetic field; blue dotted lines the electrolyte saturated with $\mathrm{O}_{2}$ and with the presence of the external magnetic field; magnetic field $B=0.56 \mathrm{~T}$
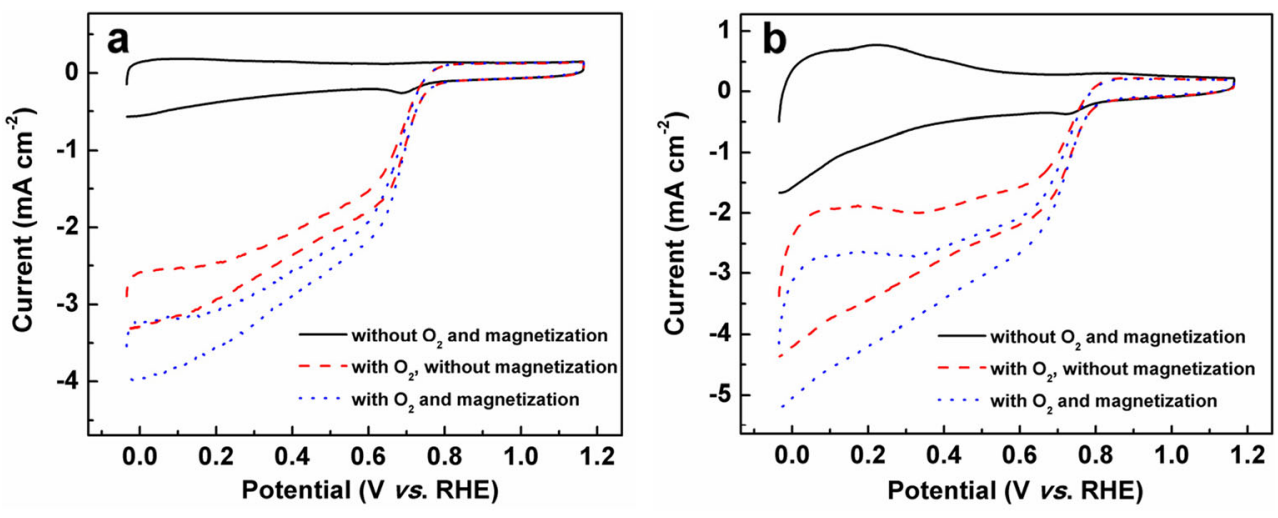
appear on the $\mathrm{Fe}_{3} \mathrm{O}_{4} / \mathrm{C}$ and $\mathrm{Fe}-\mathrm{N}-\mathrm{C}$ electrode (curves a, c), while redox peaks from $-0.035 \mathrm{~V}$ to ca. $+0.4 \mathrm{~V}$ were found on the $\gamma-\mathrm{Fe}_{2} \mathrm{O}_{3} / \mathrm{C}$ electrode, which could be related to the $\mathrm{Fe}(\mathrm{III}) / \mathrm{Fe}$ (II) redox system [19]. In addition, the capacitive currents of the $\gamma-\mathrm{Fe}_{2} \mathrm{O}_{3} / \mathrm{C}$ and $\mathrm{Fe}-\mathrm{N}-\mathrm{C}$ electrodes are much higher than that of the $\mathrm{Fe}_{3} \mathrm{O}_{4} / \mathrm{C}$ electrode, since there is no non-porous structure in $\mathrm{Fe}_{3} \mathrm{O}_{4}$.

When the solution was saturated with $\mathrm{O}_{2}$, the three electrodes showed a substantial oxygen reduction process. Herein, we only focus on the effect of the external magnetic field on the ORR activities. It was found that no obvious change of the onset potential for the three catalysts was observed when the external magnetic field was applied on the testing system. However, the currents of ORR for the three catalysts are enhanced with the presence of the external magnetic field. The results show that there is a clear promotion effect of the external magnetic field on the ORR activity, which is the same as other reports [9-11, 15]. This is caused by the Kelvin (magnetic) force which can promote the transfer of paramagnetic oxygen molecular, leading to the enhancement of the ORR current [12-14]. It is also found that the increased range of the three catalysts is not same. Here, the increase of the ORR currents related to the original ORR current at $-0.4 \mathrm{~V}$ is compared for three samples. The increase of the ORR current is $21.8,22.7$, and $26.3 \%$ for $\mathrm{Fe}_{3} \mathrm{O}_{4}, \gamma-\mathrm{Fe}_{2} \mathrm{O}_{3}$, and $\mathrm{Fe}-$ $\mathrm{N}-\mathrm{C}$, respectively. The difference of the increase of ORR currents suggests that the transfer of paramagnetic oxygen molecular under the same magnetic field is not the same for these three catalysts. A similar phenomenon was also reported by Monzon et al. [24]. However, the authors did not explain why this phenomenon occurs. To further study
Fig. 6 LSV of $\mathrm{Fe}_{3} \mathrm{O}_{4}($ a), $\gamma$ $\mathrm{Fe}_{2} \mathrm{O}_{3}(\mathbf{b})$, and $\mathrm{Fe}-\mathrm{N}-\mathrm{C}(\mathbf{c})$ in $\mathrm{O}_{2-}$ saturated $0.1 \mathrm{~mol} \mathrm{~L}^{-1} \mathrm{KOH}$ electrolyte at a scan rate of $5 \mathrm{mV} \mathrm{s}^{-1}$ and rotation rate of $1600 \mathrm{rpm}$ under the different external magnetic fields and the corresponding increased range of the ORR current at $-0.4 \mathrm{~V}$ vs. $\mathrm{Ag} / \mathrm{AgCl}$ of $\mathrm{Fe}_{3} \mathrm{O}_{4}(\mathbf{e}), \gamma-\mathrm{Fe}_{2} \mathrm{O}_{3}$ (f), and Fe-N-C (g)
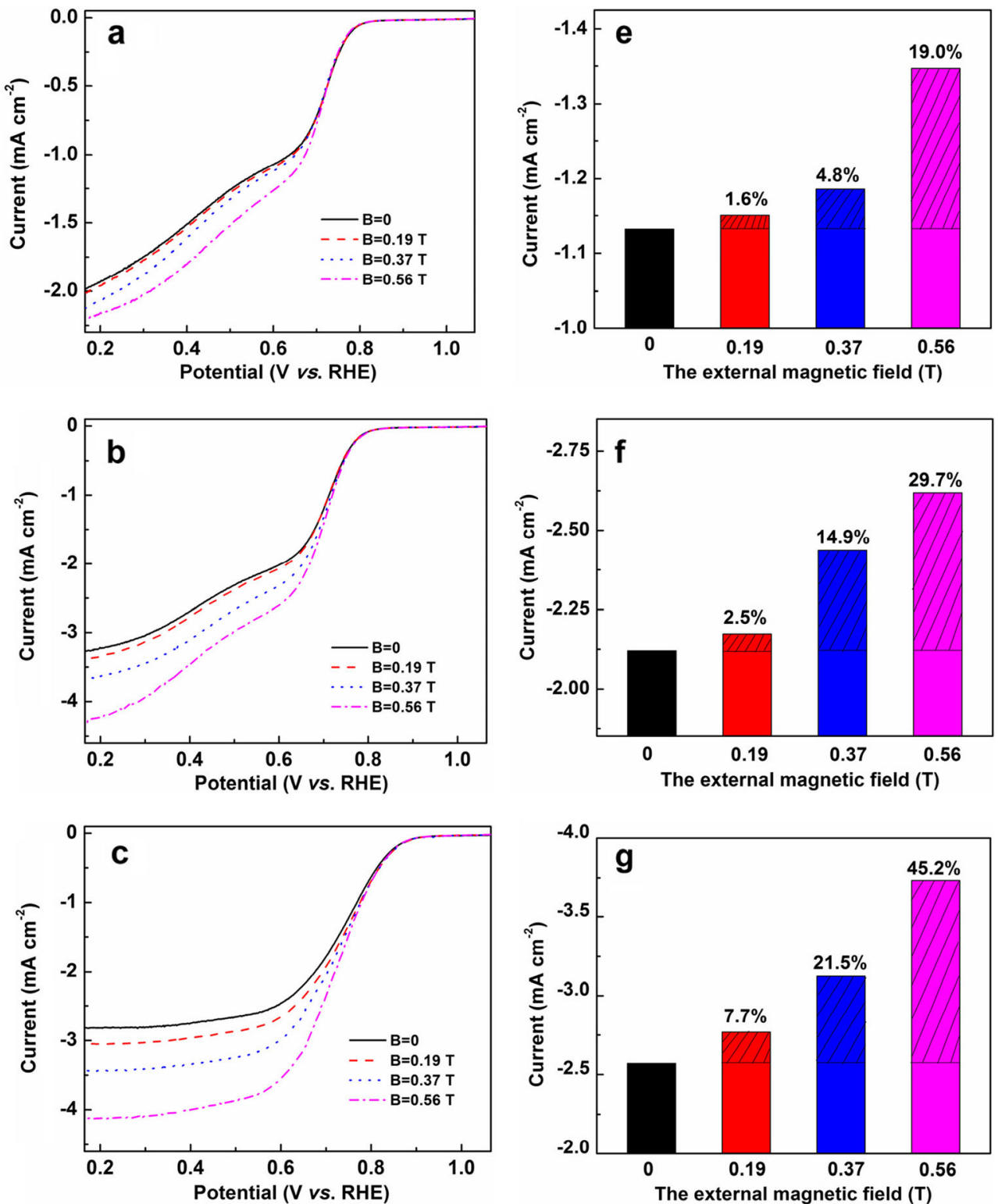
Fig. 7 Influence of the internal tiny magnetic field on $\mathrm{O}_{2}$ transfer under the external magnetic field
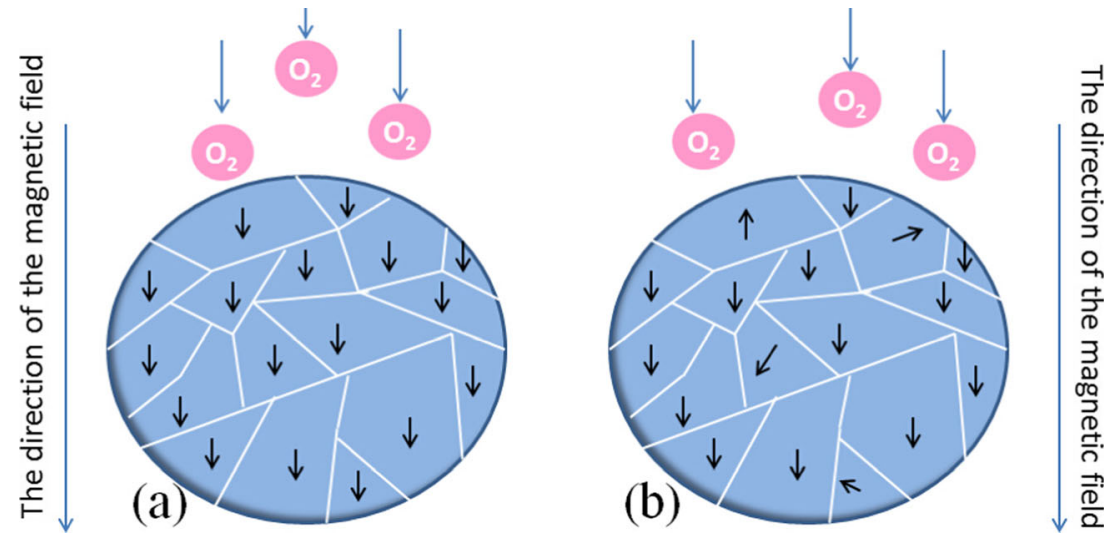

the phenomenon, linear sweep voltammetry under he different strength of the external magnetic field was carried out.

Figure 6 shows $\mathrm{LSVs}$ of $\mathrm{Fe}_{3} \mathrm{O}_{4}, \gamma-\mathrm{Fe}_{2} \mathrm{O}_{3}$, and $\mathrm{Fe}-\mathrm{N}-\mathrm{C}(\mathrm{c})$ in $\mathrm{O}_{2}$-saturated $0.1 \mathrm{~mol} \mathrm{~L}^{-1} \mathrm{KOH}$ electrolyte at a scan rate of $5 \mathrm{mV} \mathrm{s}^{-1}$ with a rotation rate of $1600 \mathrm{rpm}$, and the corresponding increased ORR current at $-0.4 \mathrm{~V}$ (vs. $\mathrm{Ag} / \mathrm{AgCl}$ ) for $\mathrm{Fe}_{3} \mathrm{O}_{4}$ (d), $\gamma-\mathrm{Fe}_{2} \mathrm{O}_{3}$ (e), and $\mathrm{Fe}-\mathrm{N}-\mathrm{C}$ (f) under different external magnetic fields. It shows that the ORR currents of the three catalysts increase with the strength of the external magnetic field. The high external magnetic field leads to the strong Kelvin (magnetic) force, which can facilitate the transfer of oxygen molecular, resulting in the higher ORR current. Meanwhile, the increased values of the ORR current are different among the three catalysts, which is similar to the results of CVs. The currents vs. strength of the external magnetic field was plotted in histograms shown in Fig. 6. It can be seen that the increased value of the ORR current under the same external magnetic field is different with each other on these three catalysts. For example, in the case of $\mathrm{Fe}_{3} \mathrm{O}_{4}$, the ORR current at $0.19 \mathrm{~T}$ increased by $1.6 \%$, while it is 2.5 and $7.7 \%$ for $\gamma-\mathrm{Fe}_{2} \mathrm{O}_{3}$ and $\mathrm{Fe}-\mathrm{N}-\mathrm{C}$, respectively. After comparing these values, the increased ORR currents of these three catalysts follow the order: $\mathrm{Fe}_{3} \mathrm{O}_{4}<\gamma-\mathrm{Fe}_{2} \mathrm{O}_{3}<\mathrm{Fe}-\mathrm{N}-\mathrm{C}$.
Fig. 8 LSVs of $\mathrm{Fe}_{3} \mathrm{O}_{4}$ (a), $\gamma$ $\mathrm{Fe}_{2} \mathrm{O}_{3}(\mathbf{b})$, and $\mathrm{Fe}-\mathrm{N}-\mathrm{C}(\mathbf{c})$ in $\mathrm{O}_{2-}$ saturated $0.1 \mathrm{~mol} \mathrm{~L}^{-1} \mathrm{KOH}$ electrolyte at a scan rate of $5 \mathrm{mV} \mathrm{s}^{-1}$ and rotation rate of $1600 \mathrm{rpm}$ under the external magnetic field $(B=0.37 \mathrm{~T})$ with the opposite direction; black line the direction of the external magnetic field is the same as that used for the previous CVs in Fig. 3 and LSVs in Fig. 5; red line the direction of the external magnetic field is opposite to that of the black line
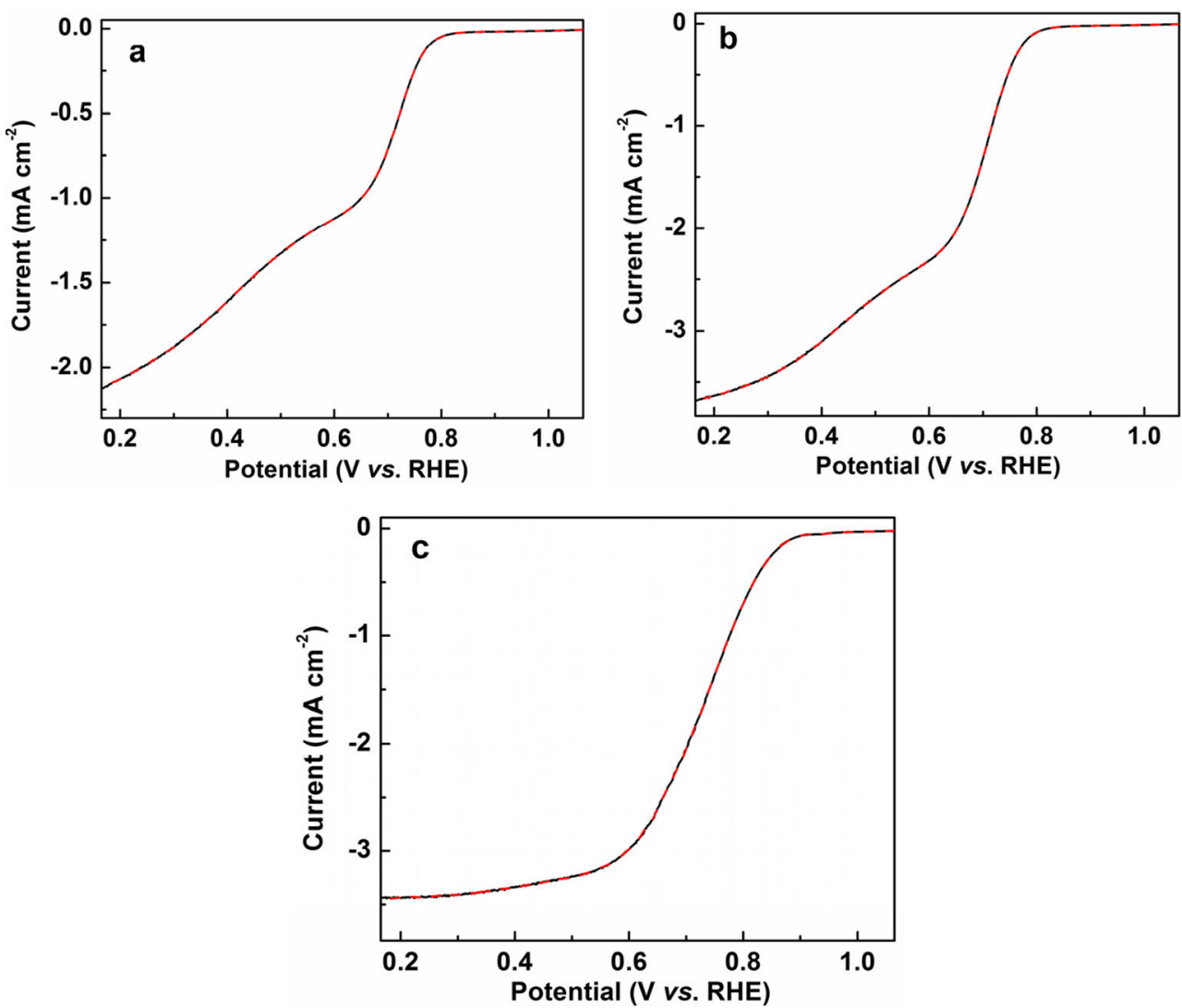
In the previous reports, the results showed that the internal tiny magnetic field of ferromagnetic catalysts can affect the catalytic performance of the cathode ferromagnetic catalysts $[16,17]$. However, Shi et al. pointed out that, when the $\mathrm{Fe}_{3} \mathrm{O}_{4} /$ polyaniline load density on the cathode electrode in a zinc air fuel cell is high at $7.11 \mathrm{mg} \mathrm{cm}^{-2}$, the tiny internal magnetic field can also inhibit oxygen transfer because of the interactions between the different magnetic poles [16]. The result implies that the influence of the tiny internal magnetic field on the catalytic performance for a cathode catalyst is a balance of these opposing factors. In this work, the three catalysts have different saturation magnetizations. When the strength of the applied external magnetic field is larger than the saturation magnetization of $\mathrm{Fe}-\mathrm{N}-\mathrm{C}$, Fe-N-C is fully magnetically saturated, implying all the tiny magnetic poles in $\mathrm{Fe}-\mathrm{N}-\mathrm{C}$ point to the same direction as the external magnetic field (as illustrated in Fig. 7a). However, for $\mathrm{Fe}_{3} \mathrm{O}_{4}$ and $\gamma-\mathrm{Fe}_{2} \mathrm{O}_{3}$, due to their high saturation magnetization, the strength of the applied external magnetic field is lower than their saturation magnetization (as illustrated in Fig. 7b), and then, there are some tiny magnets in $\mathrm{Fe}_{3} \mathrm{O}_{4}$ and $\gamma-\mathrm{Fe}_{2} \mathrm{O}_{3}$ samples, whose magnetic pole directions are different from that of the external magnetic field. When the external magnetic field was applied, the transfer of the paramagnetic oxygen molecule is promoted by the magnetic force represented by the short arrows shown in Fig. 7, leading to the increase of the ORR current in the Fe-N-C catalyst. However, in the case of $\mathrm{Fe}_{3} \mathrm{O}_{4}$ and $\gamma-\mathrm{Fe}_{2} \mathrm{O}_{3}$, some tiny magnets with different pole directions can inhibit the oxygen transfer owing to the interactions of the different magnetic poles between the paramagnetic oxygen molecules and the tiny internal magnetic fields. Thus, the presence of some tiny internal magnetic fields with different magnetic pole directions weakens the magnetic force of the external magnetic field. This may be the reason why the increased ORR currents for $\mathrm{Fe}_{3} \mathrm{O}_{4}$ and $\gamma-\mathrm{Fe}_{2} \mathrm{O}_{3}$ are lower than that of $\mathrm{Fe}-\mathrm{N}-\mathrm{C}$. In addition, the saturation magnetization of $\mathrm{Fe}_{3} \mathrm{O}_{4}$ is larger than that of $\gamma-\mathrm{Fe}_{2} \mathrm{O}_{3}$. Under the same external magnetic field, the tiny magnetic poles in $\mathrm{Fe}_{3} \mathrm{O}_{4}$ with the different magnet pole directions strongly weaken the magnetic force compared to that of $\gamma-\mathrm{Fe}_{2} \mathrm{O}_{3}$, leading to a relative low increased ORR current on $\mathrm{Fe}_{3} \mathrm{O}_{4}$ compared to $\gamma-\mathrm{Fe}_{2} \mathrm{O}_{3}$. From these results, it can be seen that the presence of the internal tiny magnetic field in the ferromagnetic catalysts with the different magnet pole directions would lessen the oxygen transfer when the strength of the applied external magnetic field is lower than the saturation magnetization.

In addition, the porosity of the catalysts may play an important role in improving the catalytic activity. When the external magnetic field was applied, the transfer of the oxygen molecule is promoted by the magnetic force. The oxygen molecules can reach the internal electroactive sites on the catalysts through the pore tunnels. For $\gamma-\mathrm{Fe}_{2} \mathrm{O}_{3}$ and $\mathrm{Fe}-\mathrm{N}-\mathrm{C}$, the porous structure facilitates the transfer of the oxygen molecule inside the electrodes, leading to the enhanced electroactive area of the catalysis. Thus, the increase of the ORR current on the $\gamma-\mathrm{Fe}_{2} \mathrm{O}_{3}$ and $\mathrm{Fe}-\mathrm{N}-\mathrm{C}$ is quite obvious when compared to the $\mathrm{Fe}_{3} \mathrm{O}_{4}$ electrode, after the external magnetic field was applied.

The effect of the direction of the external magnetic field was also studied, which was controlled by changing the input current. The obtained results are shown in Fig. 8, which show that the directions of the external magnetic field do not have any effect on the ORR current, because of the paramagnetic property of the oxygen moleculars.

\section{Conclusion}

In this study, the ferromagnetic catalysts (including $\mathrm{Fe}_{3} \mathrm{O}_{4}, \gamma-$ $\mathrm{Fe}_{2} \mathrm{O}_{3}$, and $\mathrm{Fe}-\mathrm{N}-\mathrm{C}$ ) for ORR were studied under the external magnetic fields. It was found that the magnetic force generated by the external magnetic field can facilitate the oxygen transfer, leading to the enhancement of the ORR current on the cathode; moreover, the ORR current on the cathode increases with the strength of the external magnetic field. The internal tiny magnetic field in the ferromagnetic catalysts would lessen the oxygen transfer when the applied external magnetic field is lower than the saturation magnetization of the ferromagnetic catalysts. It was also found that the direction of the external magnetic field does not affect the $\mathrm{O}_{2}$ transfer due to the paramagnetic property of the oxygen moleculars. The use of external magnets provides a new measure to improve the ORR performance for fuel cells.

Acknowledgments The authors would like to thank the National Natural Science Foundation of China (21163018, 21363022, and 51362027) for financially supporting this work.

Open Access This article is distributed under the terms of the Creative Commons Attribution 4.0 International License (http:// creativecommons.org/licenses/by/4.0/), which permits unrestricted use, distribution, and reproduction in any medium, provided you give appropriate credit to the original author(s) and the source, provide a link to the Creative Commons license, and indicate if changes were made.

\section{References}

1. Watanabe M, Tryk DA, Wakisaka M, Yano H, Uchida H (2012) Electrochim Acta 84:187-201

2. Bing Y, Liu H, Zhang L, Ghosh D, Zhang J (2010) Chem Soc Rev 39:2184-2202

3. Wang W, Wang R, Ji S, Feng H, Wang H, Lei Z, Power J (2010) Sources 195:3498-3503

4. Wu Z-S, Yang S, Sun Y, Parvez K, Feng X, Müllen K (2012) J Am Chem Soc 134:9082-9085

5. Shi C, Zang G-L, Zhang Z, Sheng G-P, Huang Y-X, Zhao G-X, Wang X-K, Yu H-Q (2014) Electrochim Acta 132:239-243 
6. Gavrilov N, Pašti IA, Mitrić M, Travas-Sejdić J, Ćirić-Marjanović G, Mentus SV, Power J (2012) Sources 220:306-316

7. Bernardi DM, Verbrugge MW (1992) J Electrochem Soc 139: 2477-2491

8. Wood DL III, Yi JS, Nguyen TV (1998) Electrochim Acta 43: 3795-3809

9. Monzon LMA, Coey JMD (2014) Electrochem Commun 42:42-45

10. Wakayama NI, Okada T, Okano J, Ozawa T (2001) Jpn J Appl Phys 40:L269

11. Okada T, Wakayama NI, Wang L, Shingu H, Okanoc J-i, Ozawac T (2003) Electrochim Acta 48:531-539

12. Wang LB, Wakayama NI, Okada T (2005) Chem Eng Sci 60: 4453-4467

13. Wang LB, Wakayama NI, Okada T (2002) Electrochem Commun 4:584-588

14. Wang LB, Wakayama NI, Okada T (2005) ISIJ Int 45:1005-1013

15. Chaure NB, Rhen FMF, Hilton J, Coey JMD (2007) Electrochem Commun 9:155-158
16. Shi J, Xu H, Zhao H, Lu L, Power J (2012) Sources 205: 129-135

17. Zeng J, Liao S, Lee JY, Liang Z (2010) Int J Hydrogen Energy 35: 942-948

18. Ma Y, Wang H, Ji S, Goh J, Feng H, Wang R (2014) Electrochim Acta 133:391-398

19. Wang R, Jia J, Wang H, Wang Q, Ji S, Tian Z (2013) J Solid State Electrochem 17:1021-1028

20. Zhang XT, Wang H, Key JL, Linkov V, Ji S, Wang XL, Lei ZQ, Wang RF (2012) J Electrochem Soc 159:B270B276

21. Wu H, Wu G, Wang L (2015) Powder Technol 269:443-451

22. Wang H, Da H, Ji S, Liao S, Wang R (2013) J Electrochem Soc 160: H266-H270

23. Ma Y, Wang H, Feng H, Ji S, Mao X, Wang R (2014) Electrochim Acta 142:317-323

24. Monzon LMA, Rode K, Venkatesan M, Coey JMD (2012) Chem Mater 24:3878-3885 